\title{
NOTES
}

\section{Surface Induced Compatibilization of Immiscible Poly(styrene-co- acrylonitrile) and Polycarbonate Blend by Short Kevlar Fiber}

\author{
Minekazu Kodama
}

\begin{abstract}
Materials \& Electronic Devices Laboratory, Mitsubishi Electric Corporation, 1-1, Tsukaguchi-Honmachi 8-chome, Amagasaki 661, Japan
\end{abstract}

(Received May 25, 1992)

\begin{abstract}
KEY WORDS Compatibility / Blend / Poly(styrene-co-acrylonitrile) /
Polycarbonate / Kevlar Fiber / Mechanical Dispersion /
\end{abstract}

It has been indicated from the theoretical studies that compatibility of an immiscible polymer blend increases at the filler surface where each polymer interacts with the surface independently. ${ }^{1}$ An immiscible nylon 6 and polypropylene blend has been shown to improve physical properties towards surfaceinduced compatibilization by mixing with the surface treated glass bead, which interacts with both components of the blend independently. ${ }^{2}$

We reported in a previous paper the apparent increase of compatibility of immiscible poly(methyl methacrylate) (PMMA) and poly(hydroxypropyl ether of bisphenol A) (PHPE) blend from the coalescence of dynamic mechanical dispersions arising from each polymer by reinforcing with Kevlar fiber. ${ }^{3}$ The occurrence of interaction of each polymer with Kevlar fiber was also shown from the infra-red spectrum. ${ }^{4}$ As the temperature interval between the main dispersions of PMMA and PHPE is, however, narrow $\left(\mathrm{ca} .20^{\circ} \mathrm{C}\right)$, the level of coalescence of the two dispersions is apt to be overestimated from the mechanical dispersion curve.

In this note the effect of adding short Kevlar fiber on the compatibility of immiscible poly(styrene-co-acrylonitrile) (SAN) and polycarbonate (PC) blend is studied from the dynamic mechanical properties and differential scanning calorimetry. In some cases, partial miscibility of one polymer in the other is shown to arise trom the observation of shifts in glass transition temperature of the two phases for melt-mixed SAN and PC blend. ${ }^{5}$ However, the blend used in this experiment may be said to be immiscible from the behaviors of glass transition of component polymers and blend as shown below and reported elsewhere, ${ }^{6}$ and the temperature interval between the main dispersions of two polymers is relatively large $\left(\mathrm{ca} .40^{\circ} \mathrm{C}\right.$ ). Short carbon fiber is also used by comparing with Kevlar fiber as a fiber with different surface functionality.

SAN used here was Sanrex-C (acrylonitrile content, $24-26 \% ; M_{w}, 200000$ ) supplied by Mitsubishi Kasei Company Monsanto Kasei Company. PC used here was Panlite K-125 $\left(M_{w}, 33000\right)$ supplied by Teijin Chemical Ltd. Kevlar fiber (Kevlar 49) was obtained from du Pont de Nemours Co., Inc. and used as a cut fiber ( $c a .0 .5 \mathrm{~mm}$ in length and $12 \mu \mathrm{m}$ in diameter). Carbon fiber (M-40) was obtained from Toray Co. and used as a cut fiber ( $c a$. $0.5 \mathrm{~mm}$ in length and $7 \mu \mathrm{m}$ in diameter). The sizing or surface treating agent of fibers was removed by washing in large amount of acetone. SAN/PC mixture at a $1: 1$ ratio by weight was dissolved in tetrahydrofuran to form a $5 \%$ solution and Kevlar fiber or carbon 


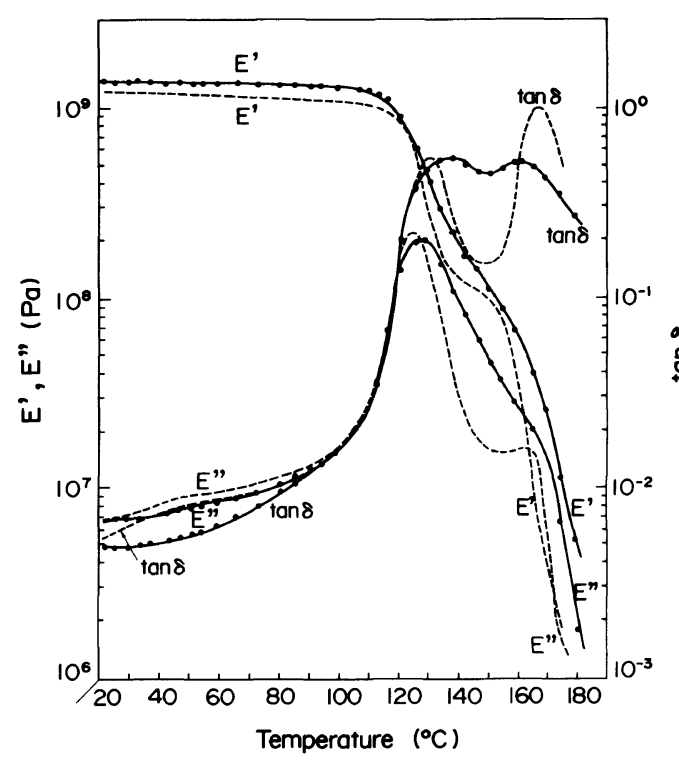

Figure 1. $E^{\prime}, E^{\prime \prime}$, and $\tan \delta v s$. temperature curves of non-reinforced blend (--) and reinforced blend with Kevlar fiber at a volume fraction of 0.09 (一-).

fiber was added to this solution and dispersed uniformly by stirring. The polymers and short fiber mixture was slowly added to a large volume of $n$-hexane, which was a non-solvent of the polymers, and was continuously stirred to coagulate the mixture. After drying the coagulated mixture in a vacuum oven, the mixture was compressed under a pressure of $3.9 \times 10^{7} \mathrm{~Pa}$ at $210^{\circ} \mathrm{C}$ for $60 \mathrm{~min}$. The specimens containing Kevlar fiber at volume fractions of $0,0.09$ and 0.18 and those containing carbon fiber at volume fraction of 0.08 and 0.15 were obtained. The dynamic mechanical properties were measured on a Rheovibron DDV-II (Toyo Boldwin Co.) at 3.5, 11, 35, and $110 \mathrm{~Hz}$. The transition temperature was obtained on a differential scanning calorimeter DSC 200 (Seiko Instruments Inc.).

As the examples the storage modulus $E^{\prime}$, loss modulus $E^{\prime \prime}$ and loss tangent $\tan \delta$ vs. temperature curves at $11 \mathrm{~Hz}$ are shown in Figures 1 and 2 for the blend containing Kevlar fiber at a volume fraction of 0.09 and for the blend containing carbon fiber at a volume

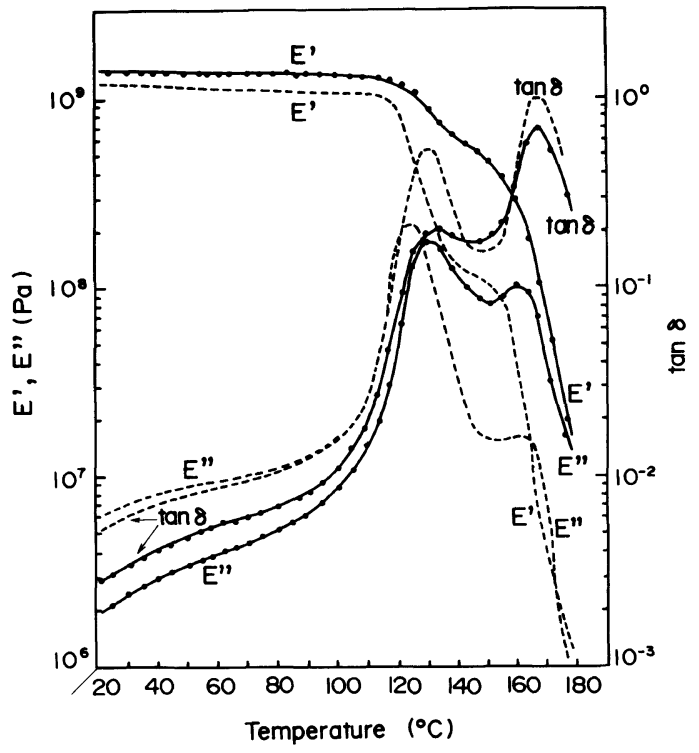

Figure 2. $E^{\prime}, E^{\prime \prime}$, and $\tan \delta v s$. temperature curves of non-reinforced blend (--) and reinforced blend with carbon fiber at a volume fraction of 0.08 ( $-\mathbf{-}-)$.

fraction of 0.08 , respectively, together with the non-reinforced blend. The features of phase separated blend can clearly be seen on $E^{\prime}, E^{\prime \prime}$, and $\tan \delta$ curves of non-reinforced blend. By reinforcing with Kevlar fiber, the low temperature dispersion shifts to the high temperature side and the high temperature dispersion shifts to the low temperature side. The similar behaviors can be observed for the reinforced blend with Kevlar fiber at a volume fraction of 0.18 . By reinforcing with the carbon fiber, the low tempeture dispersion shifts slightly to the high temperature side and the high temperature dispersion hardly changes its dispersion temperature. The similar behaviors can be observed for the reinforced blend with carbon fiber at a volume fraction of 0.15 .

The peak temperature of the low temperature dispersion $\left(T_{\mathrm{g}_{1}}\right)$, and that of the high temperature dispersion $\left(T_{\mathrm{g}_{2}}\right)$ estimated from $\tan \delta$ curve are shown in Table I. The peak temperatures of $\tan \delta$ curve of SAN $\left(T_{\mathrm{g}_{1}}\right)$, reinforced SAN with Kevlar fiber or carbon fiber $\left(T_{\mathrm{g}_{1}}\right)$, PC $\left(T_{\mathrm{g}_{2}}\right)$ and reinforced PC with 
Table I. Peak temperature of $\tan \delta$ curve $\left({ }^{\circ} \mathrm{C}\right)$

\begin{tabular}{lccc}
\hline & $T_{\mathrm{g}_{1}}$ & $T_{\mathrm{g}_{2}}$ & $T_{\mathrm{g}_{2}}-T_{\mathrm{g}_{1}}$ \\
\hline Non-reinforced blend & 132 & 169 & 37 \\
Reinforced blend with Kevlar fiber $\left(V_{\mathrm{f}}^{\mathrm{a}}, 0.09\right)$ & 137 & 163 & 26 \\
Reinforced blend with Kevlar fiber $\left(V_{\mathrm{f}}, 0.18\right)$ & 138 & 165 & 27 \\
Reinforced blend with carbon fiber $\left(V_{\mathrm{f}}, 0.08\right)$ & 134 & 169 & 35 \\
Reinforced blend with carbon fiber $\left(V_{\mathrm{f}}, 0.15\right)$ & 134 & 34 \\
SAN & 128 & & \\
Reinforced SAN with Kevlar fiber $\left(V_{\mathrm{f}}, 0.07\right)$ & 134 & 169 & 172 \\
Reinforced SAN with carbon fiber $\left(V_{\mathrm{f}}, 0.08\right)$ & & 169 \\
PC & & \\
Reinforced PC with Kevlar fiber $\left(V_{\mathrm{f}}, 0.07\right)$ & & \\
Reinforced PC with carbon fiber $\left(V_{\mathrm{f}}, 0.08\right)$ & & \\
\hline
\end{tabular}

a Volume fraction of fiber.

Kevlar or carbon fiber $\left(T_{\mathrm{g}_{2}}\right)$ are also included in Table I. For the reinforced blend with Kevlar fiber, $T_{\mathrm{g}_{1}}$ increases and $T_{\mathrm{g}_{2}}$ decreases as compared with the non-reinforced blend. For the reinforced blend with carbon fiber, $T_{\mathrm{g}_{1}}$ increases slightly and $T_{\mathrm{g}_{2}}$ hardly change as compared with the non-reinforced blend. (The effect of increasing the fiber content can not be observed definitely. This is probably because of the coagulation of fibers in matrix on account of the difficulty of uniform dispersion with incease of fiber content.) $T_{\mathrm{g}_{1}}$ of SAN increases considerably by reinforcing with Kevlar and carbon fibers. This means the occurrence of the interaction between SAN and the fibers. $T_{\mathrm{g}_{2}}$ of PC also increases by reinforcing with Kevlar fiber at somewhat smaller degrees of the increment compared with the case of SAN. $T_{\mathrm{g}_{2}}$ of PC, however, does not change by reinforcing with carbon fiber. This means that the interaction hardly arise between the carbon fiber and PC.

The shift of both $T_{\mathrm{g}} \mathrm{s}$ toward each other is an indication of compatibilization of immiscible blend. ${ }^{2,7}$ Therefore, SAN/PC blend can be said to be partially compatibilized by Kevlar fiber. The carbon fiber can not be said to compatibilize SAN/PC blend. These differences can be ascribed to the differences of interaction between the polymers and fibers mentioned above.
Table II. Apparent activation energy of two dispersions $(\Delta \mathrm{E})$ obtained from frequency dependency of peak temperature of $\tan \delta$ curve

\begin{tabular}{lcc}
\hline & \multicolumn{2}{c}{$\Delta E / \mathrm{kcal} \mathrm{mol}^{-1}$} \\
\cline { 2 - 3 } & $T_{\mathrm{g}_{1}}$ & $T_{\mathrm{g}_{2}}$ \\
\hline $\begin{array}{l}\text { Non-reinforced blend } \\
\text { Reinforced blend with Kevlar fiber } \\
\quad\left(V_{\mathrm{f}}, 0.09\right)\end{array}$ & 103 & 151 \\
$\begin{array}{l}\text { Reinforced blend with carbon fiber } \\
\left(V_{\mathrm{f}}, 0.15\right)\end{array}$ & 129 & 174 \\
& & \\
\hline
\end{tabular}

The apparent activation energies obtained from the frequency dependence of the peak temperature of $\tan \delta$ curve are shown in Table II for selected samples. The activation energies of $T_{\mathrm{g}_{1}}$ dispersion increase by reinforcement irrespective of the fibers. This probably implies the arise of interaction between the polymer components of $T_{\mathrm{g}_{1}}$ dispersion (SAN rich region) and fibers. The activation energies of $T_{\mathrm{g}_{2}}$ dispersion increase by reinforcing with Kevlar fiber and hardly change by reinforcing with carbon fiber. This implies also the arise of a more effective interaction between the polymer components of $T_{\mathrm{g}_{2}}$ (PC rich region) and Kevlar fiber. These behaviors do not contradict with the changes of $T_{\mathrm{g}} \mathrm{s}$ estimated from the dynamic mechanical properties.

The results of differential scanning calo- 
Table III. Transition temperature obtained from differential scanning calorimetry $\left({ }^{\circ} \mathrm{C}\right)$

\begin{tabular}{lcc}
\hline & $T_{\mathbf{g}_{1}}$ & $T_{\mathrm{g}_{2}}$ \\
\hline Non-reinforced blend & 107 & 147 \\
Reinforced blend with Kevlar fiber $\left(V_{f}, 0.09\right)$ & 109 & 144 \\
Reinforced blend with Kevlar fiber $\left(V_{\mathrm{f}}, 0.18\right)$ & 110 & 145 \\
Reinforced blend with carbon fiber $\left(V_{\mathrm{f}}, 0.08\right)$ & 109 & 147 \\
Reinforced blend with carbon fiber $\left(V_{\mathrm{f}}, 0.15\right)$ & 110 & 147 \\
\hline
\end{tabular}

rimetry are shown in Table III. The low temperature transition $\left(T_{\mathrm{g}_{1}}\right)$ increases slightly by reinforcing with both fibers. Though the high temperature transition $\left(T_{\mathrm{g}_{2}}\right)$ decreases slightly by reinforcing with Kevlar fiber, that does not change by reinforcing with the carbon fiber. These results qualitatively coincide with those obtained from the mechanical dispersion. Thus, Kevlar fiber can be said to have the effect of partially compatibilizing the immiscible SAN/PC blend, in which the blend components interact with the fiber independently, contrary to the blend reinforced with carbon fiber. The carbon fiber can be considered not to have the functional groups interacting with the blend components.

\section{REFERENCES}

1. Yu. S. Lipatov, in "Controlled Interphase in Composite Materials," H. Ishida, Ed., Elsevier, New York, N.Y., 1990, p 599.

2. H. Ishida and N. Scherbakoff, Makromol. Chem. Macromol. Symp., 50, 157 (1991).

3. M. Kodama and K. Kuramoto, Polym. J., 22, 21 (1990).

4. M. Kodama and I. Karino, J. Appl. Polym. Sci., 32, 5057 (1986).

5. J. D. Keitz, J. W. Balow, and D. R. Paul, J. Appl. Polym. Sci., 29, 3131 (1984).

6. M. Kodama, submitted to Polym. Eng. Sci.

7. N. K. Kalfoglou, J. Appl. Polym. Sci., 32, 5247 (1986). 